\title{
MOTIVAÇÃO DOS ESTUDANTES E DOS PROFESSORES: UM PROCESSO RECÍPROCO E RELACIONAL
}

\author{
Marina Serra de Lemos
}

Resumo: Inserindo-se num volume de homenagem ao Professor Joaquim Bairrão, impulsionador da aplicação de uma perspectiva ecológica e transaccional à investigação e prática educacional em Portugal, este texto apresenta resultados de estudos seleccionados no sentido de mostrar o interesse de uma abordagem integrada da motivação que considere a complementaridade entre as perspectivas focadas no estudante individual e as perspectivas focadas nos contextos de sala de aula. A apresentação de investigação que analisa a interdependência entre crenças motivacionais individuais dos estudantes e práticas de sala de aula, permitirá evidenciar a natureza interactiva e relacional da motivação dos estudantes e dos seus efeitos no comportamento do professor. Argumenta-se que para compreender e promover a motivação dos estudantes é necessário considerar, quer as crenças motivacionais individuais que os estudantes "trazem" consigo, quer as práticas de sala de aula. Especialmente interessantes são os resultados de investigação que mostra a existência de influências recíprocas entre professor e estudantes, os comportamentos do professor sendo determinantes e determinados pela motivação dos estudantes. Sublinha-se também o papel especial que o relacionamento professor-estudantes parece desempenhar nesta dinâmica.

Palavras-chave: motivação dos estudantes, motivação recíproca, práticas de sala de aula, relacionamento professor-estudante

Students' and teachers' motivation: A reciprocal and relational process (Abstract): This text was written to integrate a special issue in honour of Professor Joaquim Bairrão, who argued for an ecologically valid psychology of education in Portugal, which included an increased focus on the role of the social and interpersonal processes that make up the social context of schooling. Along with the spirit of his claim, this article highlights the usefulness of an integrated approach to motivation in education, emphasising a double focus on the individual and on the contextual underpinnings of student motivation. In the present article, selected studies will be presented that use an integrated analysis of student's individual beliefs and teacher's classroom practices, in order to highlight the reciprocal and relational nature of students' motivation and teacher behaviour in the classroom. It

\footnotetext{
${ }^{1}$ Faculdade de Psicologia e de Ciências da Educação, Universidade do Porto 
is argued that a more complete understanding of students' motivation entails the consideration of both the individual motivational beliefs that the students 'bring' to the classroom, and the structure and dynamics of the classroom practices. In particular, this article calls attention to the reciprocal influences between the teacher and the students, and to the need to analyse teachers' behaviours as determinants as well as consequences of students' motivation and engagement. The role played by teacher-students relationships in the motivational dynamics of the classroom is also underscored in the studies presented.

Key words: student motivation, reciprocal motivation, classroom practices, teacher-student relationships

Neste texto procura-se reunir e sistematizar contributos da literatura na área da motivação em educação que evidenciam (a) a natureza recíproca da motivação em sala de aula, destacando as cadeias cíclicas que se estabelecem entre a acção do professor e a motivação dos estudantes, a acção do professor influenciando a motivação dos estudantes, a qual, por sua vez, influencia a acção do professor e (b) o papel não apenas das práticas de instrução, mas também das relações interpessoais em sala de aula influenciando a motivação dos estudantes.

\section{Motivação e Empenho dos Estudantes}

Os padrões de motivação dos estudantes em sala de aula podem ser situados num contínuo, com dois pólos, da motivação ao desinteresse. Estes padrões de motivação envolvem componentes comportamentais e emocionais. Efectivamente, a motivação escolar designa, quer a intensidade do comportamento (quer comportamento aberto quer comportamento coberto), quer a tonalidade emocional com que o estudante inicia e desenvolve as actividades (Connell \& Wellborn, 1991; Skinner, 1991). O padrão 'motivado' caracteriza-se pela persistência comportamental acompanhada por uma tonalidade emocional positiva. Os estudantes motivados apreciam o desafio, tomam iniciativas quando lhes é dada oportunidade, esforçam-se, concentram-se e utilizam estratégias de resolução de problemas. Do ponto de vista emocional mostram-se entusiasmados, optimistas, curiosos e interessados. Em contraste, o padrão ‘desinteressado' caracteriza-se pela passividade comportamental. Quando desmotivados, os estudantes, não tentam e desistem facilmente face a obstáculos. Emocionalmente mostram-se aborrecidos, tristes ou ansiosos, ou mesmo irados por terem de estar na sala de aula, podendo retrair-se ou mesmo revoltar-se contra o professor ou contra os colegas. 
$\mathrm{Na}$ génese dos padrões motivacionais opera um conjunto de percepções e crenças individuais acerca de si e do ambiente. O modelo motivacional das necessidades psicológicas básicas (Connell \& Wellborn, 1991; Skinner \& Wellborn, 1994) concebe a instigação, manutenção e direccionamento das actividades do estudante em sala de aula como dependente da satisfação de três necessidades psicológicas básicas: a necessidade de competência, a necessidade de autonomia e a necessidade de relacionamento. Nesta perspectiva, as crenças relacionam-se com processos de auto-sistema que têm na base a satisfação destas necessidades básicas.

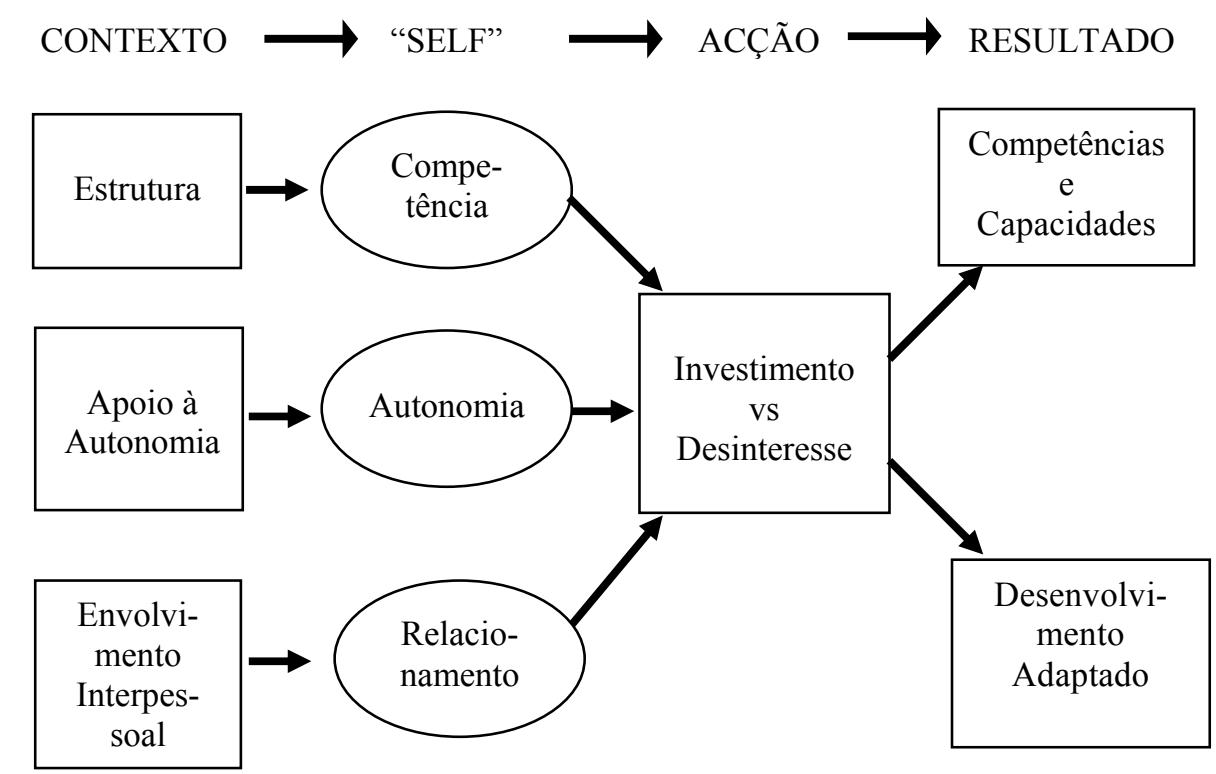

Figura 1. Modelo motivacional dos efeitos do ambiente sobre o investimento/desinteresse (Adaptado de Connell \& Wellborn, 1991)

A necessidade de competência foi inicialmente definida por White (1959) como uma necessidade psicológica básica de eficácia nas interacções com o ambiente, e posteriormente desenvolvida pelos modelos de motivação para a mestria. A necessidade de autodeterminação, enfatizada sobretudo pelas teorias da motivação intrínseca (Deci \& Ryan, 1985), sublinha o papel essencial da experiência de auto-determinação (de ser origem, autor da acção própria). A necessidade de relacionamento tem sido estudada no contexto da teoria da vinculação de Bowlby $(1982,1988)$ e Ainsworth (1989) e refere-se à necessidade de estabelecer relações próximas e seguras. 
A importância da satisfação destas três necessidades psicológicas básicas tem sido conceptualizada e investigada intensamente no âmbito da teoria da auto-determinação. Os seus fundadores (Richard Ryan e Edward Deci) acentuam que, quando as necessidades básicas são cumpridas, se verifica um sentimento de integração e crescimento pessoal. Se, pelo contrário, a pessoa sente ameaçado o preenchimento destas necessidades, surgem variadas reacções não adaptativas como a ansiedade, variando estas em função do grau de ameaça e dos recursos de que a pessoa dispõe no momento para lidar com a situação (Ryan \& Deci, 2000).

Os indivíduos desenvolvem um conjunto de crenças relacionadas com a satisfação destas três necessidades psicológicas básicas: crenças de competência, de autonomia e de segurança na relação interpessoal, respectivamente. Estas crenças reflectem-se nas interpretações e comportamentos dos indivíduos. Os que se sentem competentes, autónomos e seguros tendem a interpretar os acontecimentos como desafios conquistáveis e a tentar lidar com eles de forma eficaz. Os que desenvolvem crenças contrastantes serão mais vulneráveis a interpretações dos acontecimentos como ameaçadoras e a reacções desadaptadas.

\section{Factores contextuais de motivação}

A conceptualização que está na base do modelo motivacional das necessidades psicológicas básicas é caracterizada por um sentido organísmico, que valoriza a complementaridade crucial entre o indivíduo e o seu meio de acção. Assim, para além das necessidades psicológicas e crenças associadas, os factores contextuais desempenham neste modelo um papel influente na motivação dos estudantes.

O ambiente de sala de aula não parece afectar directamente a motivação dos estudantes, mas sim indirectamente, através dos seus efeitos nas crenças motivacionais. Por exemplo, a investigação realizada no âmbito do paradigma da motivação intrínseca identificou aspectos da sala de aula que afectam a qualidade da motivação dos estudantes através da influência sobre os seus objectivos (Ames, 1987; Deci, Connell, \& Ryan, 1985; Maehr \& Midgley, 1991). Também a investigação realizada no âmbito das teorias atribucionais analisou comportamentos do professor, tais como a ajuda não solicitada, que levavam as crianças a fazer inferências sobra as suas capacidades e esforço (Graham \& Barker, 1990).

$\mathrm{Na}$ perspectiva da teoria da auto-determinação as condições sócio-contextuais podem contribuir, por um lado para manter um nível óptimo da motivação intrínseca e, por outro lado, para facilitar a passagem de comportamentos mais motivados extrinsecamente para formas mais auto-reguladas da acção, incluindo aqui as motivações dentro do espectro externo, mas já 
mais próximas de uma maior auto-regulação (tais como a motivações integrada e identificada). A investigação realizada neste âmbito tem dado atenção à identificação dos processos que podem de algum modo potenciar ou inibir o curso natural da auto-motivação das pessoas. No que se refere ao contexto de sala de aula, o modelo representado na Figura 1 dá relevo às condições contextuais como podendo favorecer ou, pelo contrário, contrariar, a satisfação das três necessidades básicas, o que afectará as crenças motivacionais dos estudantes.

A investigação conduzida no âmbito deste modelo identificou dimensões do comportamento do professor relevantes para o empenho dos estudantes (Connell \& Wellborn, 1991). Mais especificamente, as condições contextuais que favorecem ou dificultam a satisfação das necessidades básicas e, consequentemente, as crenças dos estudantes são a estrutura versus caos, o apoio à autonomia versus coacção e o envolvimento interpessoal versus negligência.

A necessidade de competência é afectada pelo grau de estrutura da sala de aula. A estrutura refere-se à quantidade de informação existente no contexto acerca dos meios conducentes à obtenção de resultados desejados. A investigação sobre o desânimo aprendido, sobre a auto-eficácia e sobre as atribuições causais, identificou como atitudes do professor que contribuem para uma estrutura óptima, a comunicação clara das suas expectativas, a consistência e previsibilidade, a ajuda instrumental e a adequação das estratégias de ensino ao nível do estudante.

A necessidade de autodeterminação é satisfeita em função do grau de apoio à autonomia versus coação do ambiente. $\mathrm{O}$ apoio à autonomia refere-se à quantidade de liberdade dada ao indivíduo para determinar, ele próprio, o seu comportamento. $\mathrm{O}$ seu oposto é a coacção. Vários estudos mostraram (para um revisão, ver Deci \& Ryan, 1985; Grolnick, Ryan, \& Deci, 1989) que os professores podem fomentar a autonomia dos estudantes permitindo escolhas, relacionando as actividades com os seus interesses e reconhecendo a importância das suas opiniões e sentimentos, bem como minimizando os reforços externos, controlo e pressão.

Embora menos estudada no domínio escolar, a necessidade de relacionamento, de pertença e de laços seguros com colegas e professores constitui um motivo essencial para os estudantes. $\mathrm{O}$ envolvimento interpessoal refere-se à qualidade da relação interpessoal com professores e colegas e o seu oposto é a rejeição, negligência e isolamento. O professor contribui para a satisfação desta necessidade na medida em que reserva tempo para comunicar com os estudantes, exprime afecto positivo por eles, mostra prazer nas interacções, é sensível à individualidade e dedica atenção, apoio e disponibilidade aos estudantes (ver Connell \& Wellborn, 1991). 


\section{Influências recíprocas professor-estudantes}

A relação entre o comportamento do professor e a motivação dos estudantes é vista neste modelo não como resultado directo dos factores contextuais, mas como sendo mediada pelas percepções dos estudantes quanto ao grau de estrutura, apoio à autonomia e envolvimento interpessoal do professor. Percepções de boa estrutura, de oportunidades de autonomia e de relacionamento positivo levarão ao desenvolvimento de crenças de competência, de autodeterminação e de segurança relacional, as quais são necessárias para a motivação e empenho na realização.

A motivação dos estudantes não é, contudo, um processo unidireccional - do professor para o estudante - mas um processo recíproco. Nas últimas três décadas as teorias do desenvolvimento têm acentuado que as pessoas (incluindo as crianças) influenciam aqueles que as influenciam a elas. Esta participação activa no seu próprio desenvolvimento baseia-se em parte nas crenças individuais acerca de si próprio e das suas relações com o ambiente. Ao longo do desenvolvimento e em interacção com os contextos escolares, os estudantes constroem crenças de competência, de autonomia e de relacionamento, em função das quais interpretam os acontecimentos como estimulantes ou ameaçadores e agem envolvendo-se ou evitando-os. O indivíduo desempenha pois um papel central na determinação do seu comportamento, seleccionando os aspectos do ambiente a que atende, interpretando-os e reagindo aos acontecimentos. Em conjunto, estas reacções cognitivas, emocionais e comportamentais configuram padrões de motivação e empenho ou, pelo contrário, de desinteresse (Connell \& Wellborn, 1991).

O modelo pressupõe que, por sua vez, a motivação ou desinteresse dos estudantes afectará o comportamento do professor. E, em consequência do efeito que produzem nos outros, os indivíduos são alvo de reacções específicas, as quais influenciarão o seu comportamento subsequente que, por sua vez, alimenta de novo estas funções circulares. Assim, os estudantes que diferem no seu estilo comportamental colocarão requisitos educacionais diferentes aos seus professores. Será mais difícil lidar com estudantes negativistas, retraídos, com dificuldades de adaptação a novas situações, do que com estudantes que tendem a envolver-se e adaptar-se às situações e a reagir de modo positivo. Os professores responderão de forma diferente a estudantes com características diferentes. Em função das reacções de que são alvo, estes estudantes terão uma probabilidade diferente de serem bem sucedidos na aprendizagem e no desenvolvimento individual.

A dimensão relacional do comportamento do professor afecta a motivação dos estudantes 
A necessidade de afiliação/pertença - refere-se à tendência natural dos seres humanos para procurarem contacto próximo e relações íntimas com os outros, numa tentativa de atingir um sentimento de comunhão e pertença; a sua satisfação revela-se essencial para o bem-estar psicológico das pessoas (Vansteenkiste \& Sheldon, 2006). No contexto escolar, o relacionamento interpessoal do professor parece desempenhar um papel especialmente importante na motivação dos estudantes. Os estudos de Skinner em escolas do ensino básico (ver, por exemplo, Skinner \& Belmont, 1993) revelaram algumas importantes descobertas neste domínio. Neste estudo, realizado com estudantes do $3^{\circ}$ ao $5^{\circ}$ ano de escolaridade e seus professores, foram recolhidos dados no início do ano escolar, em Outubro, e de novo em Abril. As variáveis avaliadas incluíam o envolvimento emocional, estrutura e apoio à autonomia por parte do professor e o investimento emocional e comportamental do estudante. As análises focaram-se em testar cada uma das relações do modelo de relações recíprocas entre o comportamento do professor e o investimento dos estudantes, sendo de especial interesse as relações entre o comportamento do professor e o investimento dos alunos ao longo do tempo.

Através dos resultados é evidente que o calor e afecto do professor aparecem como essenciais na determinação das vivências dos estudantes em sala de aula (Figura 2).

De facto, o preditor mais consistente de todas as percepções motivacionais dos estudantes é o envolvimento interpessoal do professor. Os estudantes cujos professores revelam um elevado nível de envolvimento interpessoal sentem-se seguros na relação com eles e, para além disso, vêem-nos como oferecendo estrutura e apoio à autonomia. No mesmo sentido, os estudantes com quem o professor tem menor envolvimento interpessoal, percebem-no não apenas como menos envolvido, mas também como relativamente menos estruturado e mais coercivo e controlador.

Acresce que o investimento comportamental dos estudantes depende das suas percepções acerca da estrutura de sala de aula e, directamente, do envolvimento interpessoal do professor. Para além disso, o único preditor do investimento emocional dos estudantes é a sua percepção quanto ao envolvimento interpessoal do professor.

\section{A motivação dos estudantes influencia o comportamento do professor}

Os professores parecem alterar o seu comportamento em função das suas percepções quanto à motivação do estudante (Skinner \& Belmont, 1993). Perante um estudante desmotivado, dois tipos de reacção são teoricamente possíveis. Os professores podem

- Compensar a falta de motivação do estudante, aumentando o envolvimento interpessoal, a estruturara e o apoio à autonomia. 
Figura 2. Influências recíprocas entre o comportamento do professor e a motivação dos estudantes (Adaptado de Skinner \& Belmont, 1993)

\section{CONTEXTO}

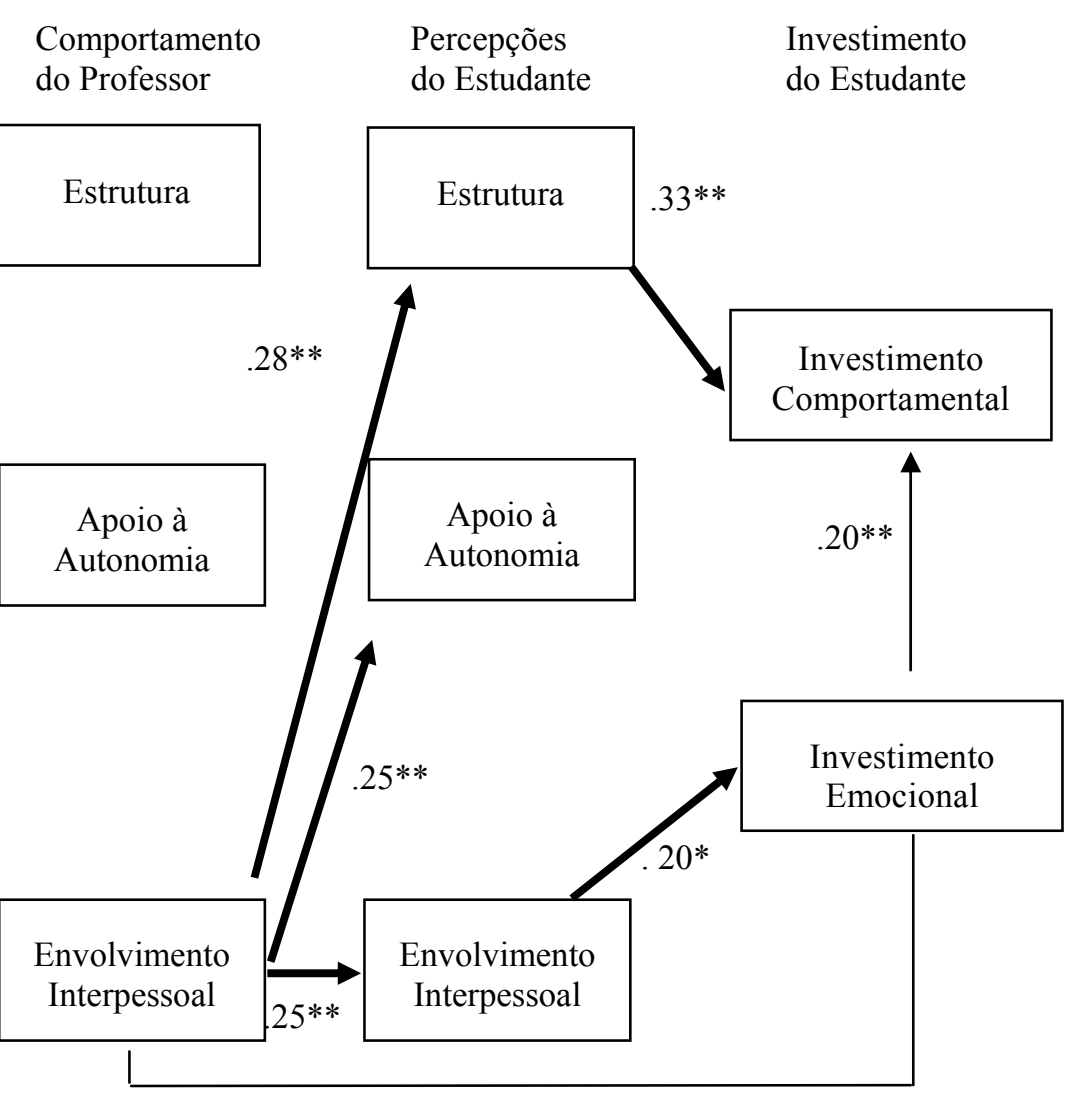

\section{ACÇÃO}

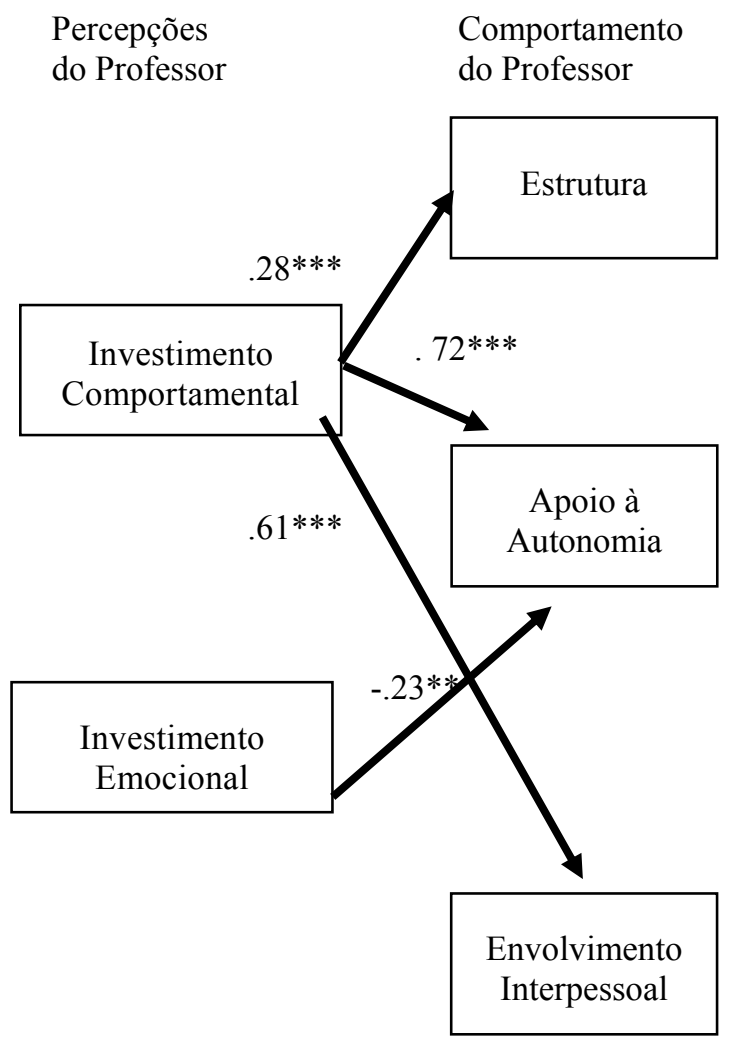


- Amplificar a falta de motivação do estudante, diminuindo o envolvimento interpessoal, a estrutura e o apoio à autonomia.

Os resultados do estudo referido sugerem que uma direcção de influência importante parece exercer-se do investimento do estudante para o comportamento subsequente do professor. Mais especificamente os estudantes percebidos pelos professores como demonstrando maior investimento comportamental (em Outubro) recebem, subsequentemente (em Abril), mais envolvimento interpessoal, e também mais apoio à autonomia e mais estrutura. Os estudantes vistos pelos professores como demonstrando menor investimento comportamental são mais ignorados/negligenciados pelo professor, mais controlados/coagidos e tratados com menor consistência e contingência (estrutura).

Ou seja, estes efeitos parecem ir no sentido da amplificação. Contudo, as percepções dos professores acerca do investimento emocional dos estudantes têm efeitos específicos. Os estudantes percebidos pelo professor como revelando uma emotividade negativa recebem mais apoio à autonomia. Isto é, contrariamente ao que se passa com o investimento comportamental, neste caso os professores compensam os estudantes que exprimem emoções mais negativas aumentando o apoio à autonomia, isto é, permitindo-lhes mais escolhas e encorajando-os a trabalhar de acordo com os seus interesses.

A investigação (ver Deci \& Ryan, 1985) tem sugerido algumas explicações para a resposta mais negativa dos professores à falta de investimento comportamental dos estudantes. A passividade dos estudantes parece ser aversiva para o professor, quer porque gera sentimentos de incompetência profissional, quer porque gera o sentimento de que o estudante não gosta dele. Em consequência o professor pode também sentir mais desagrado relativamente a estes estudantes e preferir dedicar-lhes menos tempo (aumento de negligência). A passividade dos estudantes pode também ser interpretada pelo professor como reflectindo falta de motivação interna, o que levará o professor a utilizar pressões exteriores para que participem mais (aumento da coacção).

Contudo estas explicações fariam esperar que também as emoções negativas dos estudantes face à aprendizagem fossem aversivas para o professor. É possível que o cerne da questão se encontre no tipo de emoções negativas expressas pelo estudante. No ensino básico as emoções negativas predominantes em sala de aula são a ansiedade e o aborrecimento, mais do que a ira ou depressão. Estas emoções poderão ser vistas pelo professor como um indicador de que o estudante precisa de actividades mais interessantes; neste sentido, aumenta o apoio à autonomia, diminui a pressão e o controlo.

Note-se que a relação compensadora entre o comportamento do professor e o investimento emocional dos estudantes só se verifica quando os estudantes apresentam um bom investimento comportamental. Caso contrário, a reacção dos professores é também no sentido da amplificação. 


\section{Conclusões}

Este texto pretendeu evidenciar a importância determinante do relacionamento professor-estudante na motivação e empenho dos estudantes nas actividades de sala de aula.

Uma primeira conclusão geral importante com base na investigação revista é que as interacções dos professores com os estudantes afectam o investimento comportamental e emocional destes, quer directamente, quer através do seu efeito nas percepções motivacionais dos estudantes.

Concentrando-nos no envolvimento interpessoal do professor, este parece desempenhar um papel poderoso na motivação dos estudantes. O apreço, afecto, sintonia, disponibilidade e confiança expressos pelo professor em relação aos estudantes influenciam várias percepções dos estudantes: Não apenas a percepção destes quanto ao relacionamento interpessoal com o professor, mas também quanto à consistência e estrutura do ambiente de sala de aula e quanto à autonomia. Isto significa que o envolvimento interpessoal do professor com os estudantes afecta a medida em que estes sentem que é possível agir de acordo com os seus próprios valores, interesses e personalidade ou se, pelo contrário, se sentem um joguete de excessivos constrangimentos e pressionados no sentido do conformismo. Esta dimensão relacional do comportamento do professor influencia também o investimento comportamental dos estudantes nas actividades de sala de aula. Em suma, esta investigação sugere que a relação interpessoal do professor com o estudante determinará a medida em que este sente as suas necessidades psicológicas básicas satisfeitas. Não apenas a necessidade de relacionamento, mas também as necessidades de competência e de autonomia.

Os estudantes com professores com baixo envolvimento interpessoal sentir-se-ão mais inseguros e sentem o professor como menos consistente e mais coercivo. A insatisfação das necessidades psicológicas básicas parece torná-los mais vulneráveis. De acordo com o modelo apresentado, estes efeitos operam através de mecanismos de influência que envolvem os processos de auto-sistema dos estudantes, tais como as suas crenças de competência, de autonomia e de segurança interpessoal. Menos confiantes em si e na sua relação com o mundo, os estudantes tenderão a interpretar os inevitáveis desafios colocados pelas exigências da aprendizagem como ameaçadores e a reagir defensivamente. Nomeadamente, podem evitar desenvolver esforço, não persistir, não utilizar estratégias de resolução de problemas, adquirir poucos conhecimentos e conhecimentos superficiais, desenvolver afectos negativos face ao desafio ou mesmo à situação geral de aprendizagem. Este padrão motivacional representa fragilidades, as quais aumentam a probabilidade de subsequentes insucessos na aprendizagem e desadaptação no desenvolvimento individual. 
Um segundo objectivo deste texto foi acentuar a reciprocidade da relação entre o comportamento do professor e a motivação dos estudantes em sala de aula. Em particular, a investigação apresentada evidencia o modo como o investimento do estudante também influencia o comportamento subsequente do professor. As percepções do professor acerca do investimento comportamental e emocional dos estudantes aparecem como preditoras dos seus comportamentos e atitudes subsequentes face ao estudante. Os efeitos recíprocos parecem sobretudo amplificadores. Aos estudantes que desde início demonstravam um elevado investimento comportamental, os professores respondiam com maior envolvimento interpessoal, mais apoio à autonomia e mesmo mais consistência e contingência. Face aos estudantes inicialmente mais passivos, a resposta do professor tendia a ser também correspondente, relacionando-se menos com eles, sendo mais controlador e menos consistente com estes estudantes. Dado o impacto destas reacções do professor no investimento subsequente do estudante, isto significa que os estudantes com maior investimento comportamental terão probabilidade de receber da parte do professor comportamentos e atitudes que fomentam cada vez mais a sua participação activa em sala de aula. Por sua vez, o modo como o professor lida com os estudantes que se apresentam com menor investimento comportamental tenderá a exacerbar a sua passividade e retraimento iniciais. O conhecimento destes processos cíclicos apela para a urgência de intervir nos padrões de interacção entre estudantes e professores.

Se estes ciclos habituais seguirem o seu curso típico, os professores tenderão a amplificar os níveis iniciais de investimento dos estudantes. Se para os estudantes inicialmente motivados este padrão é construtivo, para os desmotivados poderá resultar numa progressiva deterioração da sua motivação, do sucesso escolar e mesmo do desenvolvimento desadaptado. Acima de tudo, é necessário compreender os factores implicados nas diferenças entre professores quanto ao seu grau de envolvimento interpessoal, de estrutura e de apoio à autonomia, dada a sua importância para o investimento do estudante

É ainda de salientar que os fortes efeitos das percepções dos intervenientes (estudantes e professores) apontam para a importância de considerar a complementaridade das perspectivas dos estudantes e dos professores na investigação motivacional em sala de aula.

Finalmente, a formação dos professores no sentido de identificar os seus comportamentos motivacionalmente debilitantes e de adoptar comportamentos promotores do investimento dos estudantes desmotivados constitui uma prioridade da escola, quer na sua função académica, quer na sua função educacional e desenvolvimental. 


\section{Referências}

Ainsworth, M. D. (1989). Attachment relationships beyond infancy. American Psychologist, 4, 709-716.

Ames, C. (1987). The advancement of student motivation. In M. L. Maehr \& D. A. Kleiber (Eds.), Advances in motivation and achievement: Enhancing motivation (Vol. 5, pp. 123-148). Greenwich, CT: JAI Press.

Bowlby, J. (1969/1982). Attachment and loss: Attachment. New York: Basic Books ( $2^{\mathrm{a}}$ edição revista).

Bowlby, J. (1988). A secure base. London: Routledge.

Connell, J. P., \& Wellborn, J. (1991). Competence, autonomy, and relatedness: A motivational analysis of self-system processes. In M. Gunnar \& A. Sroufe (Eds.), Self processes in development: Minnesota Symposium on Child Psychology (Vol. 23, pp. 43-77). Hillsdale: Erlbaum.

Deci, E. L., \& Ryan, R. M. (1985). Intrinsic motivation and self-determination in human behaviour. New York: Plenum Press.

Deci, E. L., Connell, J. P., \& Ryan, R. M. (1985). A motivational analysis of self-determination and self-regulation in the classroom. In C. Ames \& R. Ames (Eds.), Research on motivation in education: Vol. 2. The classroom milieu (pp. 13-52). San Diego, CA: Academic Press.

Graham, S., \& Barker, G. P. (1990). The downside of help: An attributional-developmental analysis of helping behaviour as a low-ability cue. Journal of Educational Psychology, 82, 7-14.

Grolnick, W. S., Ryan, R. M., \& Deci, E. L. (1989). Parent styles associated with childrens self-regulation and competence in school. Journal of Educational Psychology, 81, 143-154.

Maehr, M. L., \& Midgley, C. (1991). Enhancing student motivation: A schoolwide approach. Educational Psychologist, 82, 399-427.

Ryan, R., \& Deci, E. (2000). Self-determination theory and the facilitation of intrinsic motivation, social development, and well-being. American Psychologist, 55(1), 68-78.

Skinner, E. A., (1991). Development and perceived control: A dynamic model of action in context. In M. R. Gunnar \& L. A. Sroufe (Eds.), Self processes in development: Minnesota Symposium on Child Psychology (Vol. 23, pp. 167-216). Chicago: University of Chicago Press.

Skinner, E. A., \& Belmont, M. J. (1993). Motivation in the classroom: Reciprocal effects of teacher behaviour and student engagement across the school year. Journal of Educational Psychology, 85 (4), 571-581.

Skinner, E. A., \& Wellborn, J. (1994). Coping during childhood and adolescence: A motivational perspective. In D. Featherman, R. Lerner \& M. Perlmutter (Eds.). Life-span development and behaviour (Vol. 12, pp. 91-133). Hillsdale, NJ: Erlbaum.

Vansteenkiste, M., \& Sheldon, K. (2006). There's nothing more practical than a good theory: Integrating motivational interviewing and self-determination theory. British Journal of Clinical Psychology, 45, 63-82.

White, R. W., (1959). Motivation reconsidered: The concept of competence. Psychological Review, 66, 297-333. 